\title{
Synthesis, Characterization, and Photocatalysis of Well-Dispersible Phase-Pure Anatase $\mathrm{TiO}_{2}$ Nanoparticles
}

\author{
Xiuzhen Wei, Guangfeng Zhu, Jinfeng Fang, and Jinyuan Chen \\ College of Biological and Environmental Engineering, Zhejiang University of Technology, \\ No. 18 ChaoWang Road, Hangzhou 310014, China
}

Correspondence should be addressed to Jinyuan Chen; cjyl128@zjut.edu.cn

Received 7 February 2013; Accepted 29 March 2013

Academic Editor: Gang Liu

Copyright (C) 2013 Xiuzhen Wei et al. This is an open access article distributed under the Creative Commons Attribution License, which permits unrestricted use, distribution, and reproduction in any medium, provided the original work is properly cited.

\begin{abstract}
High-purity anatase $\mathrm{TiO}_{2}$ nanoparticles were prepared using an improved sol-hydrothermal method. The as-prepared sample was characterized by X-ray diffraction (XRD), transmission electron microscopy (TEM), Brunauer-Emmett-Teller (BET), and UV-vis diffuse reflectance spectra. TEM results showed that the average particle size of all $\mathrm{TiO}_{2}$ particles was calculated to be $(10 \pm 1) \mathrm{nm}$. The XRD analysis indicated that the present sample was fully crystallized and appeared to be highly phase-pure anatase. The BET analysis showed that the as-prepared sample had a very large specific surface area of $186.25 \mathrm{~m}^{2} / \mathrm{g}$. The photocatalytic performance of $\mathrm{TiO}_{2}$ nanoparticles was evaluated by photocatalytic degradation of X-3B and X-BR solutions. The degradation results revealed that the as-prepared $\mathrm{TiO}_{2}$ showed slightly higher photocatalytic activities than $\mathrm{P} 25$. Whereas, the as-synthesized $\mathrm{TiO}_{2}$ can settle down and be separated easily after the photocatalytic reaction finishes.
\end{abstract}

\section{Introduction}

Titanium dioxide $\left(\mathrm{TiO}_{2}\right)$ is a versatile material with novel properties suitable for a number of technologically important applications, such as catalysis, white pigment for paints or cosmetics, electrodes in lithium batteries [1], dye-sensitized solar cells [2], and photocatalyst [3]. Although $\mathrm{TiO}_{2}$ has wide potential application in environmental management and environmental protection, the low photocatalytic efficiency and the difficulty to separate greatly hinder its process of industrialization $[4,5]$. Therefore, the key important aspect for the application of $\mathrm{TiO}_{2}$ photocatalyst is to enhance the photocatalytic efficiency and the separation efficiency.

$\mathrm{TiO}_{2}$ has three nature crystallographic phases: anatase, rutile, and brookite. Among the three main crystal phases of $\mathrm{TiO}_{2}$, rutile is the most thermodynamically stable phase, whereas anatase and brookite are metastable phases and easily transformed into rutile by thermal treatment. Anatase $\mathrm{TiO}_{2}$ is generally considered to be more active than rutile phase for $\mathrm{TiO}_{2}$ photocatalyst [6]. Anatase $\mathrm{TiO}_{2}$ with higher crystallinity is preferred for photocatalysis, due to that the higher crystallinity offers fewer defects acting as recombination sites between photo-generated electrons and holes often [7].
The physicochemical properties of the three phases are very different from each other, and they are closely related to the synthesis conditions. Anatase is the most thermodynamically stable among the three nanocrystalline phases if the size of the particles is less than $11 \mathrm{~nm}$, brookite is the most stable phase between $11 \mathrm{~nm}$ and $35 \mathrm{~nm}$, and rutile is the most stable when all the sizes are larger than $35 \mathrm{~nm}$ [8]. Thus, the synthesis conditions are very important and the synthesis parameters such as the crystal structure, surface morphology, and phase stability should be controlled and optimized.

The reported synthesis methods for $\mathrm{TiO}_{2}$ nanoparticles include gas phase method and liquid phase method. The gas phases method is very complex and high energy consumption [9], although the prepared $\mathrm{TiO}_{2}$ has a good monodispersity, a high purity, and a small size. The advantage of simple technical devices, low cost, and easy control for the liquid phase method make it widely used. The hydrolysis, solhydrothermal, microemulsion, sol-gel, and liquid deposition are the most common liquid phase methods. Among these methods, the $\mathrm{TiO}_{2}$ particles prepared by sol-hydrothermal method have good crystal model, small size, and are not easy to agglomerate. These advantages lead sol-hydrothermal method to attract vast attention in the past ten years. 
The disadvantage of this method is that the $\mathrm{TiO}_{2}$ particles need high-temperature heat treatment.

Herein, we improve the sol-hydrothermal method synthesis process which does not require high-temperature treatment, and pure anatase $\mathrm{TiO}_{2}$ nanoparticles with nanosize are obtained. XRD, BET, and TEM analyses were carried out to elucidate the as-synthesized product. The photocatalytic activity of $\mathrm{TiO}_{2}$ under UV light irradiation was evaluated by degradation reactive brilliant red $\mathrm{X}-3 \mathrm{~B}$ and reactive brilliant blue X-BR aqueous solution. This study may provide useful information and an effective approach for the preparation of high-purity anatase $\mathrm{TiO}_{2}$ nanoparticles.

\section{Experimental}

2.1. Chemicals. The chemicals included dehydrated alcohol $\left(\mathrm{CH}_{3} \mathrm{CH}_{2} \mathrm{OH}\right.$, Anhui Ante Biochemistry Co., Ltd., AR), ammonium bicarbonate $\left(\mathrm{NH}_{4} \mathrm{HCO}_{3}\right.$, Shanghai no. 4 Reagent and H.v Chemical Co., Ltd., AR), tetrabutyl titanate $\left(\mathrm{C}_{16} \mathrm{H}_{36} \mathrm{O}_{4} \mathrm{Ti}\right.$, Shanghai Star Chemical Co., Ltd. U.S., AR), P-25 (Evonik Degussa Corporation, Parsippany, NJ, USA). All the chemicals used in the experiments were of analytical purity grade with no further purification. Deionized water was used throughout the whole experiment.

2.2. $\mathrm{TiO}_{2}$ Powder Synthesis. The anatase $\mathrm{TiO}_{2}$ nanoparticles were prepared by an improved simple sol-hydrothermal method. Tetrabutyl titanate $\left(\mathrm{C}_{16} \mathrm{H}_{36} \mathrm{O}_{4} \mathrm{Ti}\right)$ was used as the titanium source. Initially $4 \mathrm{~mL}$ tetrabutyl titanate was added to $60 \mathrm{~mL}$ ethanol solution under constant stirring at room temperature. Then $80 \mathrm{~mL}$ deionized water was dropped into the solution under vigorous stirring. The obtained mixed solution was oyster white and kept under constant stirring for $30 \mathrm{~min}$. The obtained mixture and $2.0 \mathrm{~g}$ ammonium bicarbonate were transferred into a $200 \mathrm{~mL}$ Teflon-linear steel autoclave and maintained at $160^{\circ} \mathrm{C}$ for $12 \mathrm{~h}$ and then cooled to room temperature naturally finally. This produced a snowwhite colored product which was rinsed thoroughly with deionized water and dehydrated alcohol. The white product obtained was dried at $50^{\circ} \mathrm{C}$ for $12 \mathrm{~h}$. Finally, the powder was collected and transferred to a mortar and grinded to a fine powder which was used for further investigation.

2.3. Characterization. X-ray power diffraction (XRD) patterns of the samples that performed the phase identification were recorded on a $\mathrm{D} / \mathrm{max} 2550 \mathrm{Pc}$ automatic diffractometer of polycrystalline $(\mathrm{Cu} \mathrm{K} \alpha$ radiation, Rigaku-D/MAX$2500 / \mathrm{PC}$, Japan) that operated at $40 \mathrm{keV}$ and $100 \mathrm{~mA}$ over the range of $20^{\circ}<2 \theta<90^{\circ}$ at a scanning rate of $0.02^{\circ} / \mathrm{s}$. The surface areas $\left(S_{\mathrm{BET}}\right)$ of the samples were analyzed by a multipoint Brunauer-Emmett-Teller (BET) method using nitrogen adsorption/desorption isotherm measurements at $-196^{\circ} \mathrm{C}$ on an ASAP 2010 nitrogen adsorption apparatus (Micromeritics Instruments, USA). The particle size and shape were observed using transmission electron microscopy (TEM), which was equipped with an energy-dispersive X-ray spectrometry (EDS) and which was conducted with a Tecnai G2 F30 S-Twin electron microscope (Tecnai G2 F30 S-Twin,

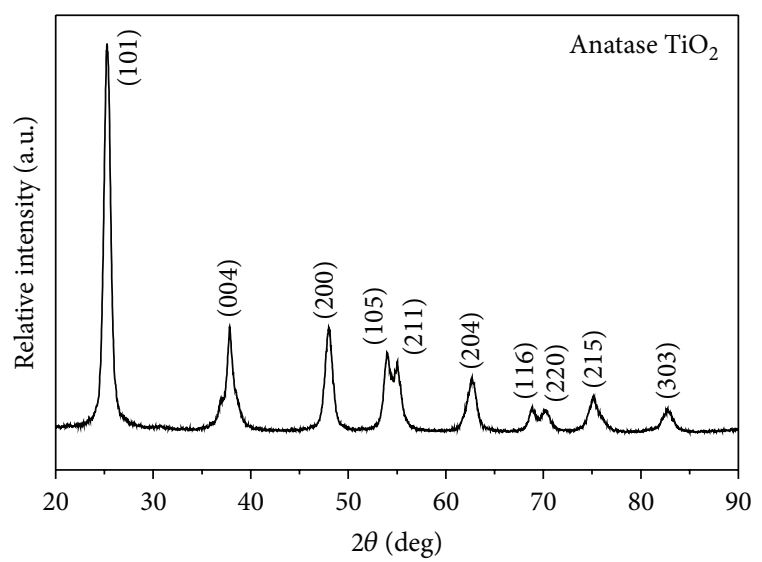

FIgURE 1: XRD patterns of the as-synthesized $\mathrm{TiO}_{2}$.

Holland) using a $300 \mathrm{kV}$ accelerating voltage with $0.20 \mathrm{~nm}$ point resolution. In addition, transmittance measurements were performed using an UV-vis spectra, obtained at room temperature with an UV-vis spectrophotometer (UV-2550, Shimadzu, Japan), with $\mathrm{BaSO}_{4}$ as the reflectance standard between $240 \mathrm{~nm}$ and $800 \mathrm{~nm}$.

2.4. Photodegradation Experiment. The degradation of reactive brilliant red $\mathrm{X}-3 \mathrm{~B}(\mathrm{X}-3 \mathrm{~B})$ and reactive brilliant blue $\mathrm{X}-\mathrm{BR}(\mathrm{X}-\mathrm{BR})$ using anatase $\mathrm{TiO}_{2}$ powder as photocatalyst in aqueous solution was examined by UV-vis absorption spectroscopy (TU-1810, Beijing, China). The light source employed in photoreactions was a $300 \mathrm{~W}$ Xe lamp (Beijing perfect light Corporation, Beijing, China). $100 \mathrm{mg}$ of asprepared $\mathrm{TiO}_{2}$ catalyst was added into $400 \mathrm{~mL}$ aqueous solution containing $20 \mathrm{mg} / \mathrm{L} \mathrm{X-3B}$ or $50 \mathrm{mg} / \mathrm{L}$ reactive brilliant blue $\mathrm{X}-\mathrm{BR}$ in a glass reactor. The solution was magnetically stirred for $20 \mathrm{~min}$ to reach the adsorption equilibrium of dye on $\mathrm{TiO}_{2}$ nanoparticles according to our previous study. Then it was irradiated by UV light. $\mathrm{TiO}_{2}$ nanoparticles free dye solutions were obtained by centrifugation at $12,000 \mathrm{rpm}$. The photocatalytic activity of Degussa P25 was also measured as a reference to be compared with that of the synthesized catalysts. The degradation efficiency of catalysts after various intervals of time can be calculated using the following equation:

$$
\text { degradation efficiency }(\%)=\frac{A_{0}-A_{t}}{A_{0}} \times 100 \text {, }
$$

where $A_{0}$ and $A_{t}$ are the initial absorbance and the absorbance after various intervals of time $(t)$, respectively. All the experiments were done at room temperature of about $25^{\circ} \mathrm{C}$.

\section{Results and Discussion}

3.1. X-Ray Diffraction. The XRD pattern of the as-synthesized sample was shown in Figure 1. The peaks of the powder materials are identified to corresponding (101), (004), (200), (105), (211), (204), (116), (220), (215), and (303) crystal planes. 
All diffraction peaks are well defined and can be perfectly assigned to the anatase $\mathrm{TiO}_{2}$ (JCPDS-21-1272). The anatase $\mathrm{TiO}_{2}$ nanoparticles were known to be very photoactive and practical for water treatment and water purification [10]. No characteristic peaks associated with other crystalline forms were detected in the XRD pattern, indicating the anatase phase-pure nature of the product. The average crystallite size of as-prepared sample was calculated to be around $10 \mathrm{~nm}$ from the peak broadening.

3.2. Transmission Electron Microscopy. Transmission electron microscopy (TEM) was used to characterize the morphology and the average size of the synthesized $\mathrm{TiO}_{2}$ nanoparticles. Typical low- and high-magnification TEM images of as-prepared $\mathrm{TiO}_{2}$ sample were shown in Figure 2. The images shown in Figures 2(a) and 2(b) revealed that the as-prepared $\mathrm{TiO}_{2}$ nanoparticles were not only uniform but also well dispersible. The well dispersible $\mathrm{TiO}_{2}$ nanoparticles may be attributed to the decomposition of ammonium bicarbonate $\left(\mathrm{NH}_{4} \mathrm{Cl}\right)$. When tetrabutyl titanate is hydrolyzed into $\mathrm{TiO}_{2}, \mathrm{NH}_{4} \mathrm{Cl}$ is decomposed into $\mathrm{NH}_{3}, \mathrm{H}_{2} \mathrm{O}$, and $\mathrm{CO}_{2}$ and large amounts of bubbles are produced in the mixed solution. Large amount of energy is released when the bubbles burst which is similar to the cavitations effect produced by ultrasound [11]. The energy produced by the burst of bubbles will prevent the agglomeration of synthesized $\mathrm{TiO}_{2}$ [12].

The average particle size of the $\mathrm{TiO}_{2}$ particles was calculated to be $(10 \pm 1) \mathrm{nm}$ from Figures $2(\mathrm{c})$ and $2(\mathrm{~d})$. The minimum and maximum particle sizes were lying close to average particle size. The particles size calculated from the TEM images was well consistent with the XRD values.

3.3. BET Surface Area Analysis. The typical plot of $\mathrm{N}_{2}$ adsorption-desorption isotherm and pore size distribution curves of as-prepared $\mathrm{TiO}_{2}$ sample was shown in Figure 3(a). The sample exhibited isotherm of type IV (BDDT classification) with hysteresis loops of type $\mathrm{H} 3$ at relative pressure range of $0.65-1.0$, indicating the presence of mesoporous structure [13]. The corresponding pore size distribution of the sample was shown in Figure 3(b). The pore size distributions indicated that $\mathrm{TiO}_{2}$ presented a relatively narrow distribution ranging from $5 \mathrm{~nm}$ to $25 \mathrm{~nm}$. Taking into account the morphology of the material observed by TEM, the small pores should be the intra nanoparticles pores. The BET surface area of the prepared $\mathrm{TiO}_{2}$ nanoparticles was $186.25 \mathrm{~m}^{2} / \mathrm{g}$ and the BET surface area of commercial P25 was $50 \mathrm{~m}^{2} / \mathrm{g}$. A larger surface area provides more surface active sites for the adsorption of the reactive molecules, which leads the photocatalytic process to be more efficient [14]. We can draw the conclusion that the nanoparticles prepared by us might have good photocatalytic activities.

\subsection{UV-Vis Absorption Spectra of X-3B Solution Degraded by} Synthesized $\mathrm{TiO}_{2}$. The UV-vis absorption spectrum of the X$3 \mathrm{~B}$ aqueous solution degraded by UV-irradiation using asprepared $\mathrm{TiO}_{2}$ as catalyst was shown in Figure 4. The results clearly demonstrated that the X-3B aqueous solution exhibited four significant absorption peaks at $280 \mathrm{~nm}, 315 \mathrm{~nm}$,
$375 \mathrm{~nm}$, and $535 \mathrm{~nm}$, respectively. According to the theory of spectrum, we speculate that the absorption characteristic peak at $280 \mathrm{~nm}$ belongs to the aromatic functional group which represents benzene and naphthyl of X-3B. The absorption characteristic peaks at 315 and $375 \mathrm{~nm}$ represent Azo bond of $\mathrm{X}-3 \mathrm{~B}$. The strongest absorption characteristic peak at $535 \mathrm{~nm}$ is caused by conjugated structures which makes the $\mathrm{X}-3 \mathrm{~B}$ solution appear to have the characteristic red. The results indicate that the Azo bond is easy to be broken by the influence of UV light and $\mathrm{TiO}_{2}$. Due to that the Azo bond is unstable, the color of $\mathrm{X}-3 \mathrm{~B}$ solution can change easily. In this study, the concentration of $\mathrm{X}-3 \mathrm{~B}$ was found to be less than $1 \%$ after $80 \mathrm{~min}$ of UV irradiation. In other words, the degradation rate was more than $99 \%$ within $80 \mathrm{~min}$.

3.5. Photocatalytic Activities. Generally speaking, the high photocatalytic degradation rate corresponds to the high photocatalytic activity. The photocatalytic ability of assynthesized sample was evaluated by UV-degradation X$3 \mathrm{~B}$ and $\mathrm{X}-\mathrm{BR}$ solutions. Figure 5 illustrates the degradation rate of $\mathrm{X}-3 \mathrm{~B}$ and $\mathrm{X}-\mathrm{BR}$ in the presence of the obtained $\mathrm{TiO}_{2}$ and the commercial P25. The results exhibit that the obtained $\mathrm{TiO}_{2}$ reveals slightly higher photocatalytic activities than P25. The best degradation rate of X-3B and X-BR for the obtained $\mathrm{TiO}_{2}$ reaches $99.5 \%$ and $96.08 \%$, respectively. Actually, it is very difficult to find a photocatalyst showing higher photocatalytic activity than P25 used as a standard titania photocatalyst [15]. As is our known, the activity of semiconductor photocatalysts depends on the specific surface area, composition, crystal size, and so on. $\mathrm{TiO}_{2}$ has three wellknown crystallographic phases in nature: anatase, rutile, and brookite. According to the reference reported, the anatase phase possesses the best photocatalyst. The phase ratio of anatase to rutile for commercial P25 used in our paper was 80 to 20 and the specific surface area was $50 \mathrm{~m}^{2} / \mathrm{g}$. However, our synthesized $\mathrm{TiO}_{2}$ was phase-pure anatase $\mathrm{TiO}_{2}$ and the specific surface area was $186.25 \mathrm{~m}^{2} / \mathrm{g}$. The pure anatase phase and relative high specific area endow the synthesized $\mathrm{TiO}_{2}$ relative higher photocatalytic activity. What should be noted is that the synthesized $\mathrm{TiO}_{2}$ can settle down and be separated easily by simple decantation in one step compared with the commercial P25. The results indicate that the prepared $\mathrm{TiO}_{2}$ can be prepared easily and has a well promising application prospect in photocatalysis field.

The proposed photocatalytic process illuminated with UV light for $\mathrm{TiO}_{2}$ may be as the following. When $\mathrm{TiO}_{2}$ solution is irradiated by UV light, the conduction band electrons (e-) and valence band holes $(\mathrm{h}+)$ are generated on $\mathrm{TiO}_{2}$ surface as long as the light energy equals or exceeds the band gap energy [16]. The holes can react with surface hydroxyl ions or water molecules producing hydroxyl radicals $(\bullet \mathrm{OH})$, and electrons can react with adsorbed oxygen molecules yielding superoxide anion radicals $\left(\bullet \mathrm{O}_{2}{ }^{-}\right)$[17], which act as the oxidizing agents and the additional source of hydroxyl radicals. The hydroxyl radicals are the strongest oxidizing agent which can react with dye molecules and lead to the purification of dye wastewater. 


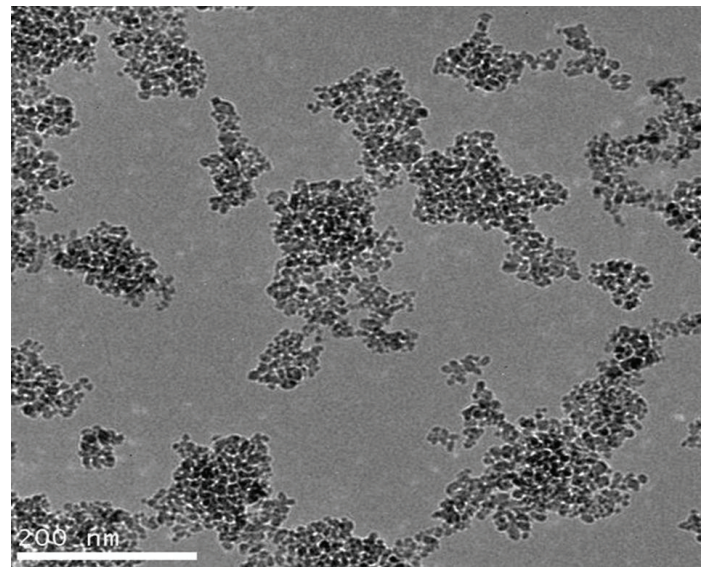

(a)

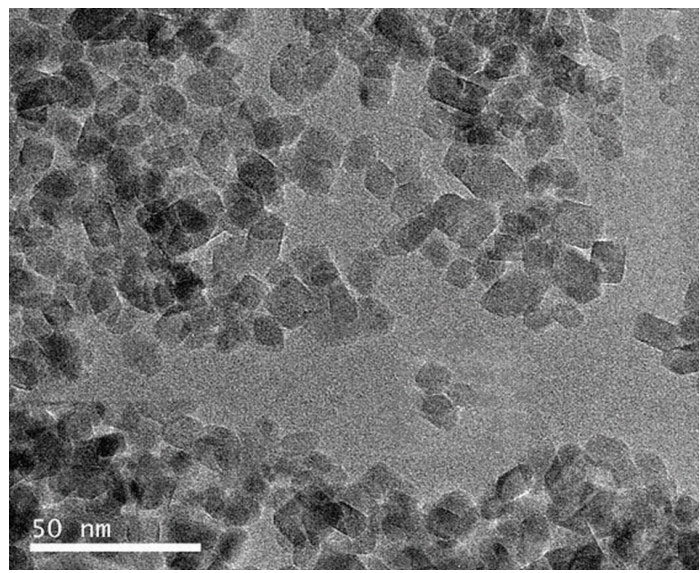

(c)

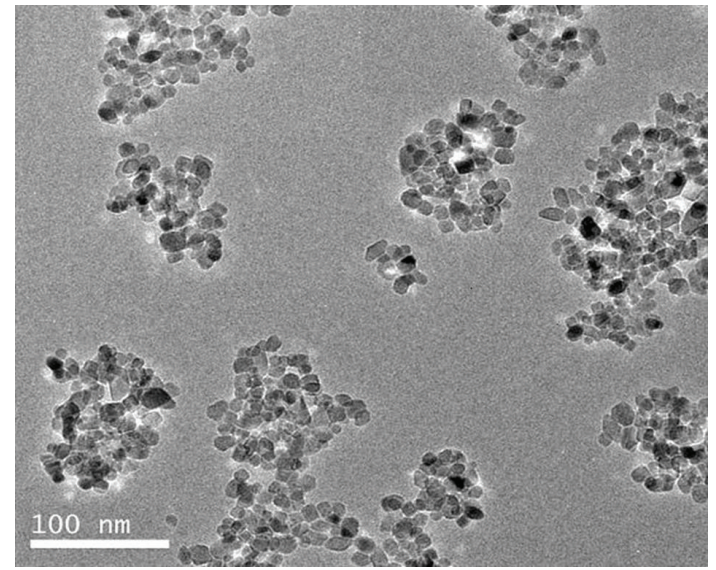

(b)

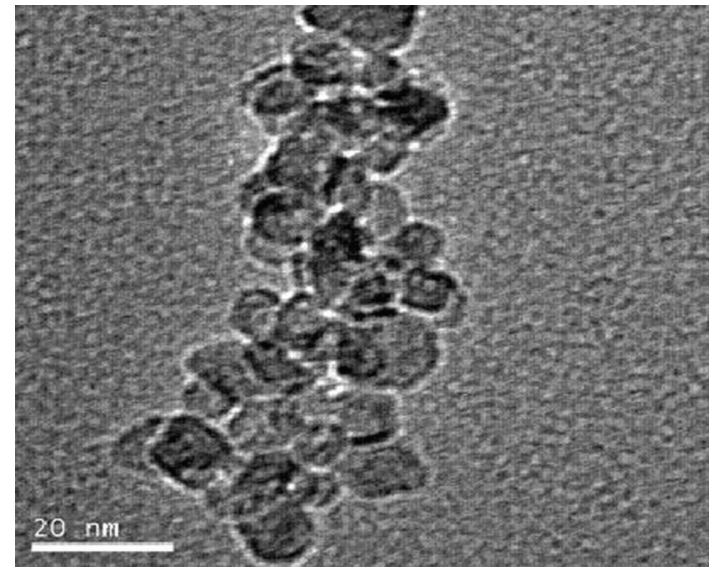

(d)

FIgURE 2: TEM images of the as-synthesized $\mathrm{TiO}_{2}$ in different magnifications.

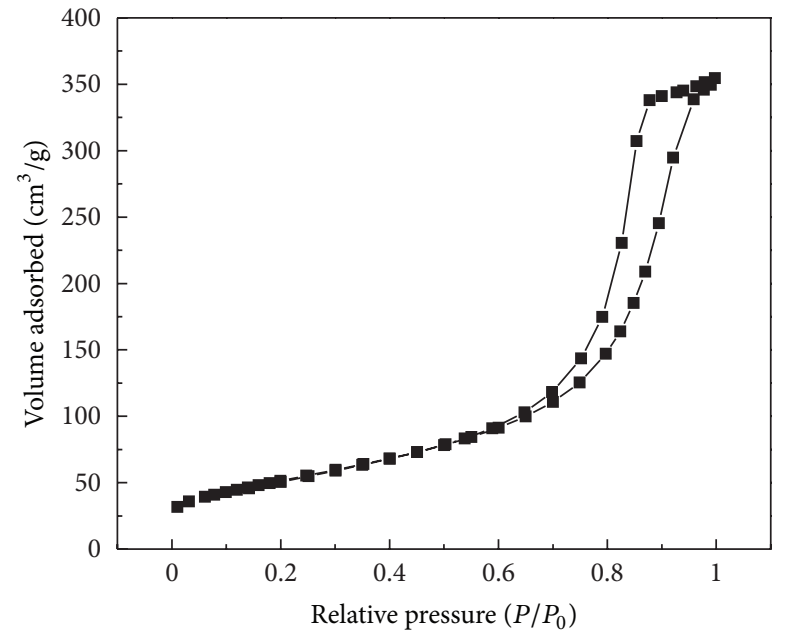

(a)

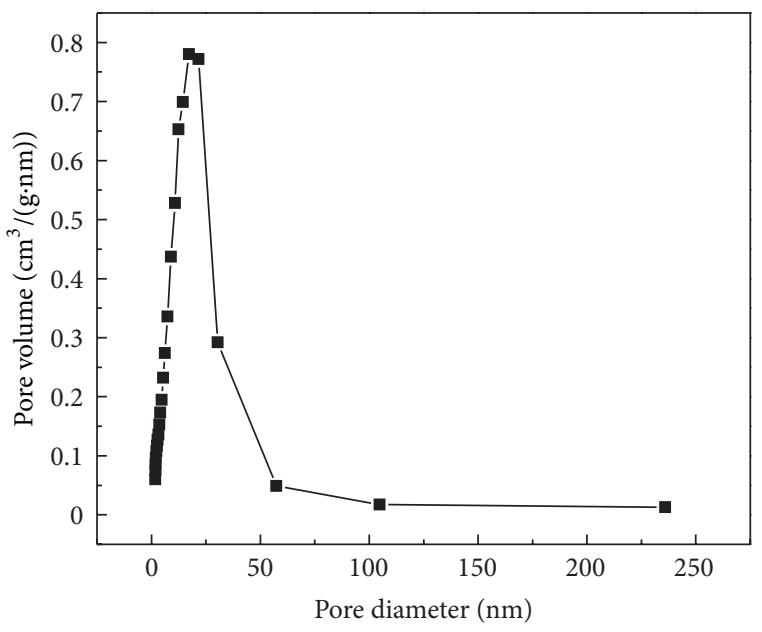

(b)

FIGURE 3: (a) Nitrogen adsorption-desorption isotherms and (b) corresponding pore size distribution curves of the as-synthesized $\mathrm{TiO}_{2}$. 


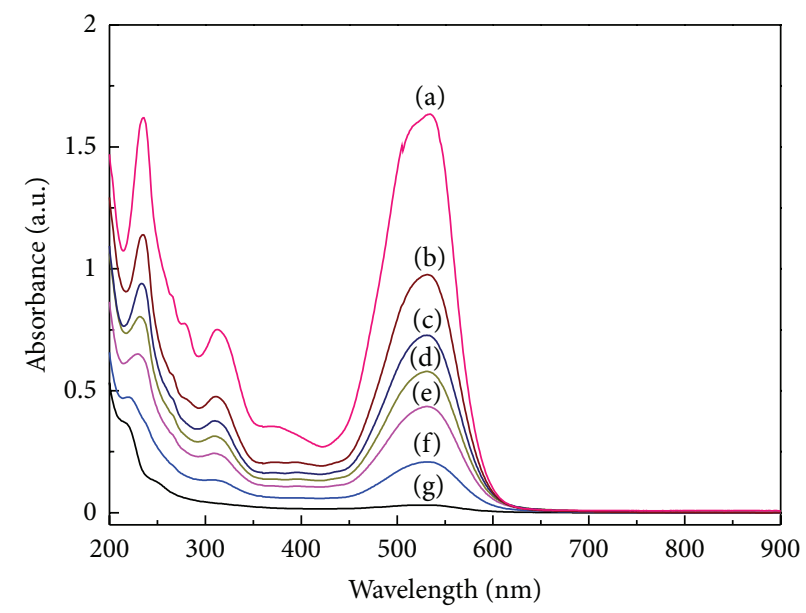

$\begin{array}{ll}- \text { (a) } 0 \mathrm{~min} & - \text { (e) } 40 \mathrm{~min} \\ \text { (b) } 10 \mathrm{~min} & - \text { (f) } 60 \mathrm{~min} \\ \text { (c) } 20 \mathrm{~min} & - \text { (g) } 80 \mathrm{~min} \\ \text { (d) } 30 \mathrm{~min} & \end{array}$

FIGURE 4: UV-vis spectra of X-3B solution as a function of wavelength for various time intervals.

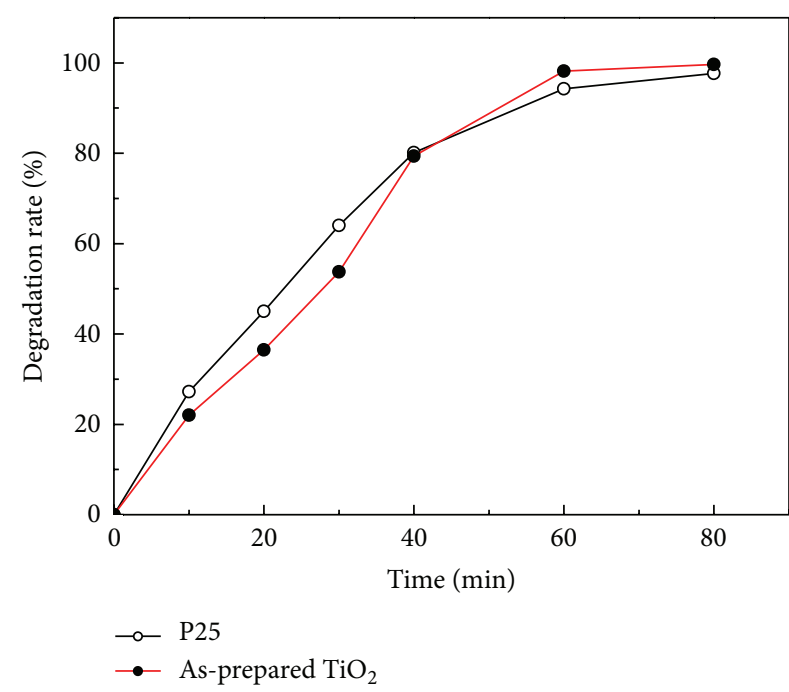

(a)

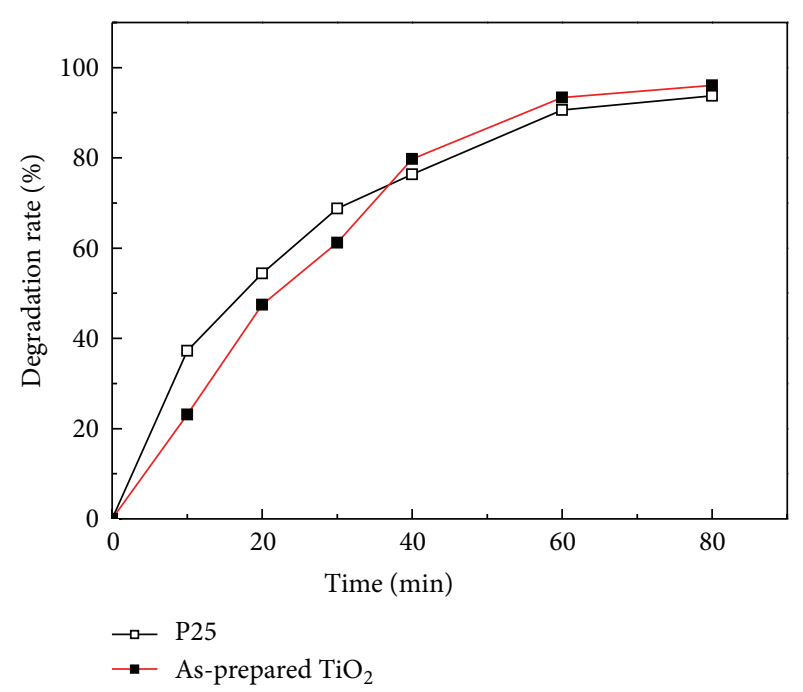

(b)

FIGURE 5: Photocatalytic degradation rate curves of different dye molecules as a function of irradiation time under UV light: (a) X-3B, (b) $\mathrm{X}-\mathrm{BR}$.

\section{Conclusions}

A facile method for the synthesis of pure-phase anatase $\mathrm{TiO}_{2}$ nanoparticle has been developed. Compared with most of the prior arts, the prepared sample does not need to calcine at high temperature for this method, which can reduce energy consumption and production cost efficiently. Analysis by different characterization techniques (XRD, TEM, BET, and $\mathrm{UV}$-vis) indicated that the as-prepared $\mathrm{TiO}_{2}$ was pure-phase anatase and uniformly dispersed. The photocatalytic activity of the prepared sample was assessed using X-3B and X-BR solutions and compared with that of the commercial P25. The results indicated that $\mathrm{X}-3 \mathrm{~B}$ and $\mathrm{X}-\mathrm{BR}$ molecules were degraded effectively and the degradation rate reached $99.5 \%$ and $96.08 \%$, respectively, within 80 mins. And the prepared sample shows slightly better photocatalytic activity than that of $\mathrm{P} 25$. What is more is that the synthesized $\mathrm{TiO}_{2}$ can settle down and be separated easily.

\section{Acknowledgment}

Financial support from the Natural Science Foundation of China (no. 20877070 and no. 21177114) is gratefully acknowledged.

\section{References}

[1] A. R. Armstrong, G. Armstrong, J. Canales, and P. G. Bruce, " $\mathrm{TiO}_{2}-\mathrm{B}$ nanowires as negative electrodes for rechargeable 
lithium batteries," Journal of Power Sources, vol. 146, no. 1-2, pp. 501-506, 2005.

[2] H. Park, W. R. Kim, H. T. Jeong, J. J. Lee, H. G. Kim, and W. Y. Choi, "Fabrication of dye-sensitized solar cells by transplanting highly ordered $\mathrm{TiO}_{2}$ nanotube arrays," Solar Energy Materials and Solar Cells, vol. 95, no. 1, pp. 184-189, 2011.

[3] T. Ochiai and A. Fujishima, "Photoelectrochemical properties of $\mathrm{TiO}_{2}$ photocatalyst and its applications for environmental purification," Journal of Photochemistry and Photobiology C, vol. 13, no. 4, pp. 247-262, 2012.

[4] X. B. Chen and S. S. Mao, "Titanium dioxide nanomaterials: synthesis, properties, modifications, and applications," Chemical Reviews, vol. 107, no. 7, pp. 2891-2959, 2007.

[5] M. Anpo, "Preparation, characterization, and reactivities of highly functional titanium oxide-based photocatalysts able to operate under UV-visible light irradiation: approaches in realizing high efficiency in the use of visible light," Bulletin of the Chemical Society of Japan, vol. 77, no. 8, pp. 1427-1442, 2004.

[6] K. Tanaka, T. Hisanaga, P. Rivera, D. F. Ollis, and H. Al-Ekabi, Photocatalytic Purification and Treatment of Water and Air, Elsevier, Amsterdam, The Netherlands, 1993.

[7] D. He and F. Lin, "Preparation and photocatalytic activity of anatase $\mathrm{TiO}_{2}$ nanocrystallites with high thermal stability," Materials Letters, vol. 61, no. 16, pp. 3385-3387, 2007.

[8] A. Furube, T. Asahi, H. Masuhara, H. Yamashita, and M. Anpo, "Charge carrier dynamics of standard $\mathrm{TiO}_{2}$ catalysts revealed by femtosecond diffuse reflectance spectroscopy," Journal of Physical Chemistry B, vol. 103, no. 16, pp. 3120-3127, 1999.

[9] G. H. Li, D. Chen, G. X. Yao, B. Shi, and C. Ma, "Preparation

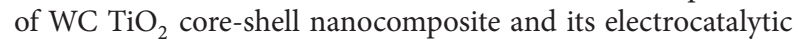
characteristics," Chinese Journal of Chemical Engineering, vol. 19, no. 1, pp. 145-150, 2011.

[10] S. J. Kim, M. F. A'Hearn, D. D. Wellnitz, R. Meier, and Y. S. Lee, "The rotational structure of the B-X system of sulfur dimers in the spectra of Comet Hyakutake (C/1996 B2)," Icarus, vol. 166, no. 1, pp. 157-166, 2003.

[11] J. Y. Chen, H. J. Wang, and X. Z. Wei, "Characterization, properties and catalytic application of $\mathrm{TiO}_{2}$ nanotubes prepared by ultrasonic-assisted sol-hydrothermal method," Materials Research Bulletin, vol. 47, no. 11, pp. 3747-3752, 2012.

[12] P. Ding and A. W. Pacek, "De-agglomeration of goethite nano-particles using ultrasonic comminution device," Powder Technology, vol. 187, no. 1, pp. 1-10, 2008.

[13] J. G. Yu, H. G. Yu, B. Cheng, and C. Trapalis, "Effects of calcination temperature on the microstructures and photocatalytic activity of titanate nanotubes," Journal of Molecular Catalysis A, vol. 249, no. 1-2, pp. 135-142, 2006.

[14] J. G. Yu, W. G. Wang, and B. Cheng, "Synthesis and enhanced photocatalytic activity of a hierarchical porous flowerlike pn junction $\mathrm{NiO} / \mathrm{TiO}_{2}$ photocatalyst," Chemistry, vol. 5, no. 12, pp. 2499-2506, 2010.

[15] B. Ohtani, O. O. Prieto-Mahaney, D. Li, and R. Abe, "What is Degussa (Evonic) P25? Crystalline composition analysis, reconstruction from isolated pure particles and photocatalytic activity test," Journal of Photochemistry and Photobiology A, vol. 216, no. 2-4, pp. 179-182, 2010.

[16] T. Y. Han, C. F. Wu, and C. T. Hsieh, "Hydrothermal synthesis and visible light photocatalysis of metal-doped titania nanoparticles," Journal of Vacuum Science and Technology B, vol. 25, no. 2, pp. 430-435, 2007.
[17] Y. F. Tu, S. Y. Huang, J. P. Sang, and X. W. Zou, "Preparation of Fe-doped $\mathrm{TiO}_{2}$ nanotube arrays and their photocatalytic activities under visible light," Materials Research Bulletin, vol. 45 , no. 2, pp. 224-229, 2010. 

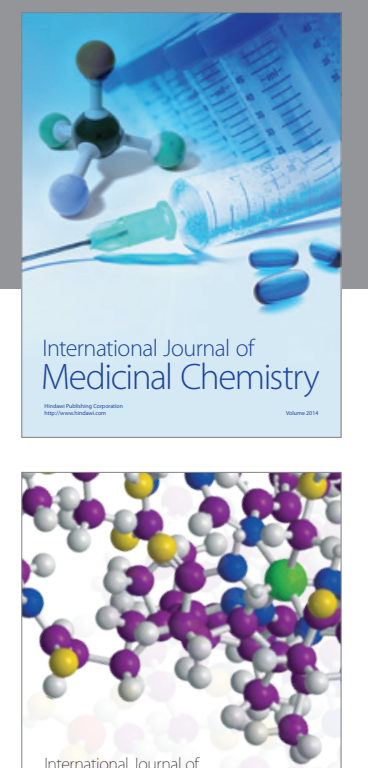

\section{Carbohydrate} Chemistry

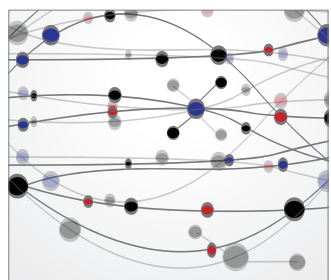

The Scientific World Journal
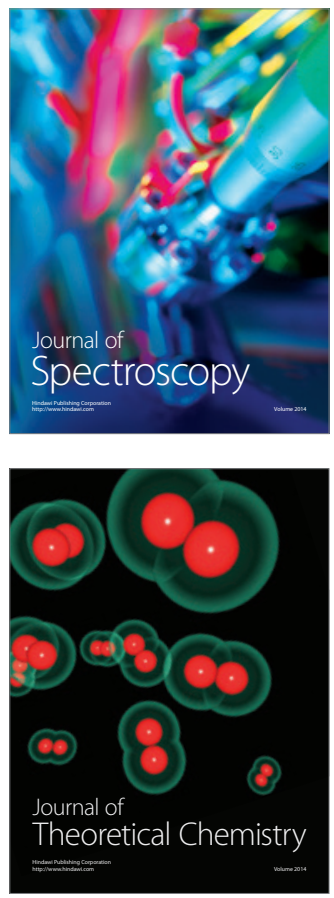
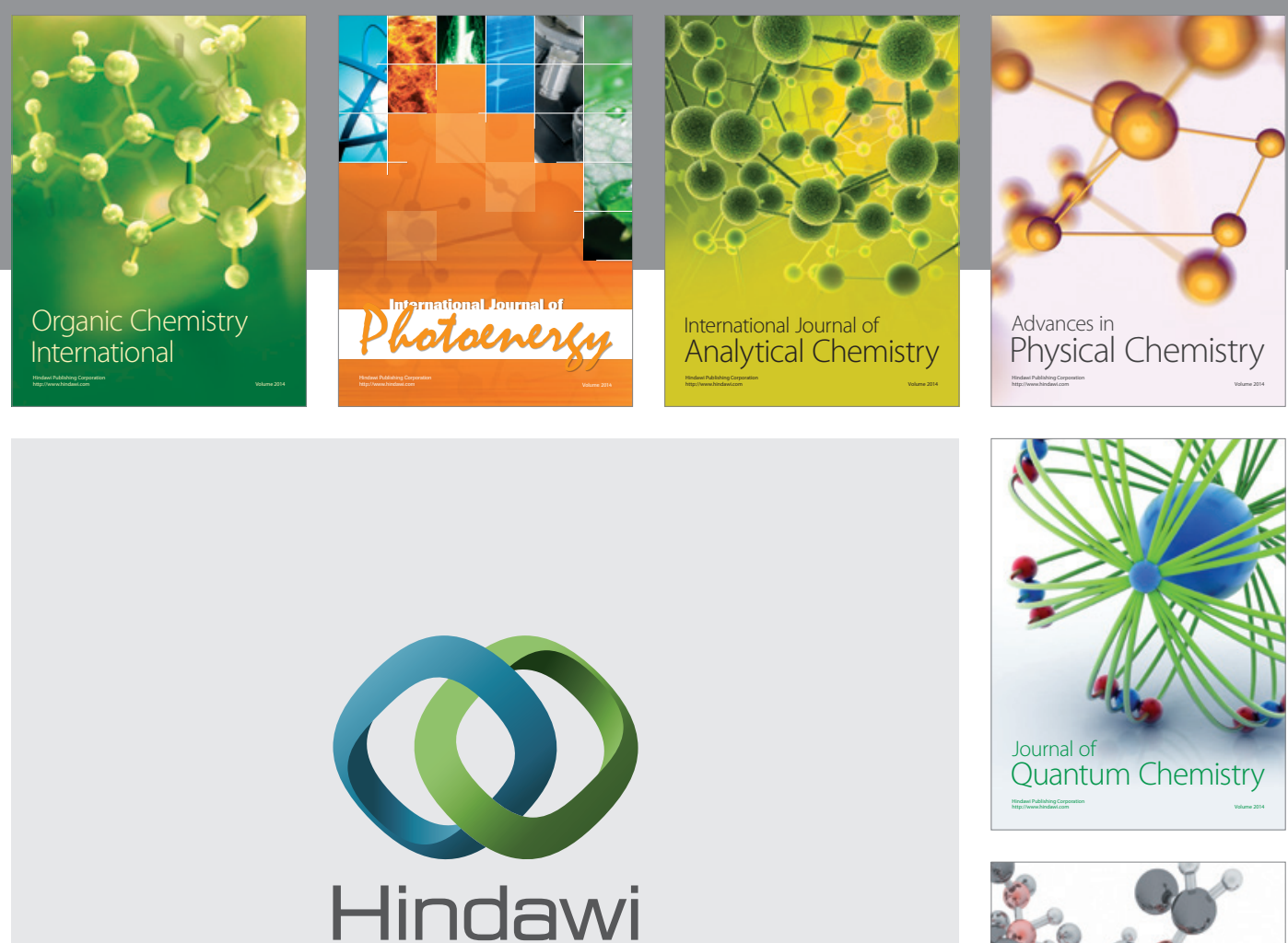

Submit your manuscripts at

http://www.hindawi.com

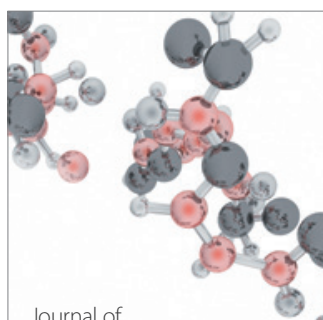

Analytical Methods

in Chemistry

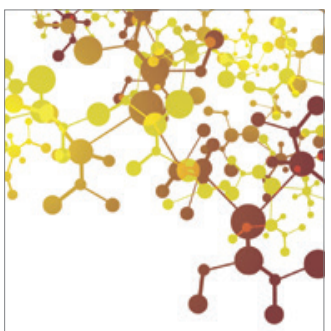

Journal of

Applied Chemistry

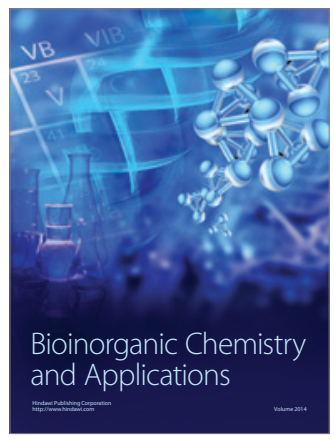

Inorganic Chemistry
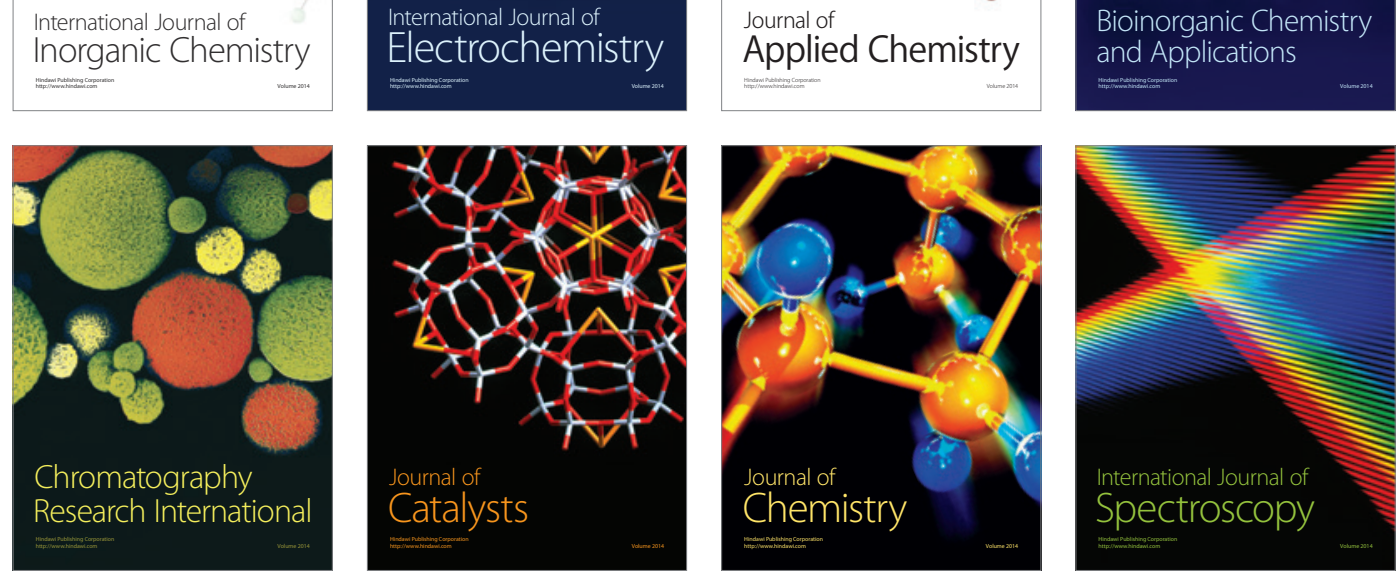